\title{
Prediction of mortality and morbidity in patients with secondary peritonitis using POMPP scoring
}

\author{
Ankit Bhatia, Shantanu Kumar Sahu, Santhosh Kumar \\ Himalayan institute of medical sciences, Swami Rama Himalayan University, Dehradun, Uttarakhand, \\ India
}

Keywords: POMPP; secondary peritonitis; mortality; morbidity

\begin{abstract}
\section{Introduction}

"POMPP [Practical scoring system of mortality in patients with perforated peptic ulcer] is a simple, clinically applicable scoring system that may allow surgeons to rapidly predict mortality rates in patients based on objective data."
\end{abstract}

This study was aimed at using the POMPP scoring in secondary peritonitis patients for rapid assessment, to predict the mortality and morbidity and to validate POMPP scoring.

\section{Methodology}

This observational study was conducted on patients with suspected secondary peritonitis at the Himalayan Institute of Medical Sciences, Dehradun over a period of 12 months from January 2017 to December 2017.

All patients fulfilling inclusion criteria were included with written informed consent. The parameters under evaluation for each patient under the POMPP scoring were Age [ $>65$ years], serum albumin $[<1.5 \mathrm{gm} / \mathrm{dl}]$ and blood urea nitrogen $[>45 \mathrm{mg} / \mathrm{dl}]$, with each parameter having a score of 1 . Risk of mortality and complications associated with POMPP score were analysed using statistical tests including chi square test, student $\mathrm{t}$ test and Fisher exact test. A $\mathrm{p}$ value $<0.05$ was considered statistically significant.

\section{Results}

During the study period a total of 138 patients undergoing laparotomy for peritonitis were enrolled and evaluated. There were $86[62.3 \%], 42$ [30.4\%], 9 [6.5\%] and 1 [0.7\%] patients with scores of $0,1,2$ and 3, respectively. Additionally, the postoperative complications were broadly divided into local, respiratory, renal, cardiovascular, systemic and anastomotic complications. Local Complications were found to be most common with 38 [27.5\%] patients. Study of mortality associated with each score revealed there was 3.5\% mortality Correspondence: Shantanu Kumar Sahu

E-mail: lntshantanu@yahoo.co.in

Received:11-01-2019Accepted: 24-04-2020

(iD) http://orcid.org/0000-0003-2898-6329

DOI: http://doi.org/10.4038/sljs.v38i1.8565

The Sri Lanka Journal of Surgery 2020; 38(1): 36-41 with score $0,16.7 \%$ with score $1,44.4 \%$ with score $2,100 \%$ with score 3 thus indicating that the gravest prognosis lies with patients who present with a POMPP score of 3 . However, there was only one patient who had POMPP score 3. This observation of increasing POMPP score with relation to mortality was deemed statistically significant $[p<0.05]$ using Fisher's exact test.

\section{Conclusions}

Gastrointestinal perforation and secondary peritonitis patients have been shown to have a strong association with advanced age, blood urea nitrogen and serum albumin levels. Analysis of these simple clinical and biochemical parameters in our study has helped in validation of the POMPP scoring system for risk stratification of cases of secondary peritonitis. It has been observed to be a simple, clinically applicable scoring system that may allow surgeons to rapidly predict morbidity and mortality rates in all types of gastrointestinal perforations.

\section{Introduction}

Gastrointestinal perforations are a major cause of mortality \& morbidity. Peritonitis due to perforation is one of the commonest surgical emergencies attended by a general surgeon. Perforation peritonitis has a varied clinical profile and several scoring systems have been used to predict prognosis of patients with peritonitis.

"Practical scoring system of mortality in patients with perforated peptic ulcer[PPOMPP] is a simple, clinically applicable scoring system that may allow surgeons to rapidly predict mortality rates in patients with perforated peptic ulcers [PPU]" [1].

Table 1. POMPP Score

\begin{tabular}{|l|l|}
\hline POMPP variable & Points \\
\hline Age $>65$ years & 1 \\
\hline Albumin $<1.5 \mathrm{~g} / \mathrm{dl}$ & 1 \\
\hline BUN $>45 \mathrm{mg} / \mathrm{dl}$ & 1 \\
\hline Total score & $0-3$ \\
\hline
\end{tabular}


Table 2. POMPP score assigned to subjects

\begin{tabular}{|l|l|l|}
\hline $\begin{array}{l}\text { POMPP } \\
\text { Score }\end{array}$ & $\mathrm{N}=\mathbf{1 3 8}$ & $\%$ \\
\hline $\mathbf{0}$ & 86 & $62.3 \%$ \\
\hline $\mathbf{1}$ & 42 & $30.4 \%$ \\
\hline $\mathbf{2}$ & 9 & $6.5 \%$ \\
\hline 3 & 1 & $0.7 \%$ \\
\hline Total & 138 & $100.0 \%$ \\
\hline
\end{tabular}

Table 3. POMPP score with Type of Perforation

\begin{tabular}{|l|l|l|l|l|}
\hline $\begin{array}{c}\text { POMPP } \\
\text { Score }\end{array}$ & \multicolumn{2}{|c|}{$\begin{array}{c}\text { Non Peptic } \\
\text { n=81 }\end{array}$} & \multicolumn{2}{c|}{$\begin{array}{c}\text { Peptic } \\
\text { n=57 }\end{array}$} \\
\hline $\mathbf{0}$ & 49 & $60.5 \%$ & 37 & $64.9 \%$ \\
\hline $\mathbf{1}$ & 25 & $30.9 \%$ & 17 & $29.8 \%$ \\
\hline $\mathbf{2}$ & 6 & $7.4 \%$ & 3 & $5.3 \%$ \\
\hline $\mathbf{3}$ & 1 & $1.2 \%$ & 0 & $0.0 \%$ \\
\hline Total & 81 & $100.0 \%$ & 57 & $100.0 \%$ \\
\hline
\end{tabular}

Table 4. POMPP Score with Morbidities

\begin{tabular}{|c|c|c|c|c|c|c|}
\hline \multirow[t]{2}{*}{ Morbidities } & \multicolumn{4}{|c|}{ POMPP Score } & \multirow{2}{*}{$\begin{array}{c}\text { Total } \\
{[n=138]}\end{array}$} & \multirow[t]{2}{*}{ p-value } \\
\hline & $0[n-86]$ & $1[n-42]$ & $2[n-9]$ & $3[n-1]$ & & \\
\hline \multirow[t]{2}{*}{ Local Complications } & 20 & 14 & 4 & 0 & 38 & 0.367 \\
\hline & $23.3 \%$ & $33.3 \%$ & $44.4 \%$ & $0.0 \%$ & $27.5 \%$ & \\
\hline \multirow[t]{2}{*}{ Respiratory Complications } & 12 & 8 & 2 & 0 & 22 & 0.799 \\
\hline & $14.0 \%$ & $19.0 \%$ & $22.2 \%$ & $0.0 \%$ & $15.9 \%$ & \\
\hline \multirow[t]{2}{*}{ Renal Complications } & 2 & 6 & 0 & 0 & 8 & 0.045 \\
\hline & $2.3 \%$ & $14.3 \%$ & $0.0 \%$ & $0.0 \%$ & $5.8 \%$ & \\
\hline \multirow[t]{2}{*}{ CVS Complications } & 0 & 2 & 2 & 0 & 4 & $<0.01$ \\
\hline & $0.0 \%$ & $4.8 \%$ & $22.2 \%$ & $0.0 \%$ & $2.9 \%$ & \\
\hline \multirow[t]{2}{*}{ Systemic Complications } & 3 & 4 & 5 & 0 & 12 & $<0.01$ \\
\hline & $3.5 \%$ & $9.5 \%$ & $55.6 \%$ & $0.0 \%$ & $8.7 \%$ & \\
\hline \multirow[t]{2}{*}{ Anastomotic Complications } & 6 & 2 & 2 & 0 & 10 & 0.324 \\
\hline & $7.0 \%$ & $4.8 \%$ & $22.2 \%$ & $0.0 \%$ & $7.2 \%$ & \\
\hline
\end{tabular}

Table 5. POMPP score with Mortality in Comparison with Non Peptic and Peptic

\begin{tabular}{|c|c|c|c|c|}
\hline \multirow{2}{*}{$\begin{array}{c}\text { POMP } \\
\text { P score }\end{array}$} & \multicolumn{2}{|c|}{ Non peptic n=81 } & \multicolumn{2}{c|}{ Peptic $\mathbf{n = 5 7}$} \\
\cline { 2 - 5 } & \multicolumn{2}{|c|}{ Mortality } & \multicolumn{2}{c|}{ Mortality } \\
\hline $\mathbf{0}$ & 2 & $4.1 \%$ & 1 & $2.7 \%$ \\
\hline $\mathbf{1}$ & 5 & $20.0 \%$ & 2 & $11.8 \%$ \\
\hline $\mathbf{2}$ & 3 & $50.0 \%$ & 1 & $33.3 \%$ \\
\hline $\mathbf{3}$ & 1 & $100.0 \%$ & 0 & $0.0 \%$ \\
\hline TOTAL & 11 & $13.6 \%$ & 4 & $7.0 \%$ \\
\hline
\end{tabular}

Table 6. POMPP Score with Mortality

\begin{tabular}{|c|c|c|c|c|c|}
\hline \multirow[t]{2}{*}{ Mortality } & \multicolumn{4}{|c|}{ POMPP Score } & \multirow{2}{*}{$\left.\begin{array}{c}\text { Total } \\
{[n=138}\end{array}\right]$} \\
\hline & 0 & 1 & 2 & 3 & \\
\hline \multirow[t]{2}{*}{ Yes } & 3 & 7 & 4 & 1 & 15 \\
\hline & $3.5 \%$ & $16.7 \%$ & $44.4 \%$ & $100.0 \%$ & $10.9 \%$ \\
\hline \multirow[t]{2}{*}{ Total } & 86 & 42 & 9 & 1 & 138 \\
\hline & $100.0 \%$ & $100.0 \%$ & $100.0 \%$ & $100.0 \%$ & $100.0 \%$ \\
\hline & & $p-v a$ & $<0.01$ & & \\
\hline
\end{tabular}


Table 7. Duration of hospital stay with POMPP score

\begin{tabular}{|c|c|c|c|}
\hline $\begin{array}{c}\text { POMPP } \\
\text { Score }\end{array}$ & $\mathbf{N}$ & Mean & SD \\
\hline $\mathbf{0}$ & 87 & 9.34 & 5.60 \\
\hline $\mathbf{1}$ & 41 & 9.76 & 5.69 \\
\hline $\mathbf{2}$ & 9 & 11.67 & 8.47 \\
\hline $\mathbf{3}$ & 1 & 3.00 & $\cdot$ \\
\hline Total & 138 & 9.57 & 5.83 \\
\hline
\end{tabular}

This study was aimed at using the POMPP scoring in secondary peritonitis patients for rapid assessment, to predict the mortality and morbidity and to validate POMPP scoring.

\section{Materials and methods}

The observational study was conducted on patients with suspected perforation peritonitis at the Himalayan Institute of Medical Sciences, Dehradun over a period of 12 months from January 2017 to December 2017. This study was conducted with the ethical approval from the internal ethical committee.

All clinically diagnosed cases of perforation peritonitis with investigatory support and absence of evidence of primary or tertiary aetiology were included in the study with written informed consent.

All patients who fulfilled the inclusion criteria underwent the following

- All the relevant clinical details of history and physical examinations and investigations were recorded as per the pre-set format.

- Patients were investigated accordingly and POMPP variables were taken and POMPP score was calculated

- Operative procedure and site of perforation was recorded.

- All mortalities occurring among the study subjects, irrespective of cause, were noted.

- The patients were followed up by the principle investigator to assess morbidities at 24 hour intervals in the post-operative period till the patient was either discharged or till mortality during the course of the admission. The specific morbidities were assessed using classifications given by Dindo et al [2]

- Local complications i.e. Surgical Site Infection, Wound Dehiscence, Pelvic Abscess, Prolonged Ileus and Burst Abdomen were assessed clinically

- CVS complications i.e. Bradycardia and Atrial Fibrillation were assessed clinically and confirmed with electrocardiogram
Table 8. Logistic regression analysis of the POMPP variables with mortality

\begin{tabular}{|c|c|c|c|c|c|}
\hline \multicolumn{5}{|c|}{ Logistic Regression: Mortality [Y/N] } \\
\hline Variables & S.E. & p- value & Odds Ratio & \multicolumn{2}{|c|}{$\mathbf{9 5 \% ~ C l}$} \\
\hline & & & & Lower & Upper \\
\hline Age & 0.02 & $\mathbf{0 . 1 2}$ & 1.031 & 0.992 & 1.072 \\
\hline Albumin & 0.716 & $<0.01$ & 0.065 & 0.016 & 0.263 \\
\hline BUN & 0.013 & $\mathbf{0 . 5 8}$ & 1.007 & 0.982 & 1.033 \\
\hline
\end{tabular}

- Systemic complications i.e. Altered Sensorium, Thrombocytopenia and Shock with clinical assessment and haematological investigations

- Renal complications i.e. Acute Renal Failure and haematuria with biochemical derangements, urine output and urine analysis

- Respiratory complications i.e. URTI, Pleural Effusion and ARDS with clinical assessment, Arterial blood gas analysis and radiological evaluation i.e. X ray chest

- Gastrointestinal / Anastomotic complications i.e. Ileal leak \& Enterocutaneous fistula with clinical assessment, content and output

Data was collected in a specially designed case recording form. The data collected was then transferred into a master chart which was subjected to statistical analysis using SPSS version 22 .

The parameters under evaluation for each patient under the POMPP scoring were their age, serum albumin and blood urea nitrogen and a score was awarded as per following [Table 1]:

Data Management and Statistical Analysis:

- Analysis of obtained results was carried out using software [SPSS version 22] by application of descriptive methods [eg. mean, proportion, rate etc].

- For quantitative data or variable, parametric statistical tests of significance were used.

- The data collected from each study subject and tabulated into the master chart was evaluated using standard statistical tests such as chi square test, student t test and Fisher's Exact test. A 5\% significance level was considered in all statistical tests.

\section{Results}

During the study period a total of 138 patients undergoing laparotomy for peritonitis were enrolled and evaluated. Most patients $[n=54,39.1 \%]$ were in the age group 25-45 years. Only $5.8 \%[n=8]$ patients were above the age of 65 years, 
which was one of the parameters. There was an overwhelming preponderance of males in the study with $89.9 \%$. The second parameter of POMPP score assessed patients with serum albumin level less than $1.5 \mathrm{gm} / \mathrm{dl}$, which were found to be $10.9 \%[n=15]$ while final parameter was patients with BUN level more than 45 which were noted to be $16.7 \%$ [n=23]. As per these observations, our study showed that among the score that was assigned before undergoing laparotomy following result was noted:

Among all patients with perforation peritonitis, 57 patients [41.3\%] had peptic perforations while other 81 [58.7\%] were of non-peptic sites while only one patient had a POMPP 3. Of the non-peptic perforations ileal was the commonest site of perforation accounting for 31 cases [38.3\%], followed by jejunal which were 11 [13.6\%] and appendicular perforation were 10 [12.3\%]. There were also caecal $[n=7]$ and Gall Bladder perforations $[\mathrm{n}=5]$. Rest included colonic, ileocecal, rectal perforations and perforations of multiple sites.

In our study the postoperative complications were studied as an indicator of disease associated morbidity. These were broadly divided into local, respiratory, renal, cardiovascular, systemic and anastomotic complications. The following table [Table 4] shows various complications and their significance at different scores. Fisher's exact test was applied to assess the significance of each complication. Local Complications were found to be most common being noted among $27.5 \%$ patients. Of the total 138 patients, $42.9 \%$ of patients had some disease associated morbidity, out of which non peptic group had $40.7 \%$ morbidity while the peptic group had $45.6 \%$ morbidity.

Mortality outcomes were calculated separately for peptic and non-peptic groups [Table 5]. There was $13.6 \%$ risk of mortality in non-peptic group while there was $7.0 \%$ risk in peptic group.

An overall of risk of $10.9 \%$ mortality was noted in all gastrointestinal perforations studied which was significant based on Fisher's exact test $[\mathrm{p}<0.01]$. [Table 6]

Table 7 illustrates the mean duration of hospital stay noted amongst patients was 9.57 days with standard deviation of 5.83 days. Hospital stay was found to positively correlating using Spearman correlation $[\mathrm{r}=0.0658]$ with increasing POMPP score. Non peptic group had an average of 10.51 days while peptic group had 8.25 days.

Further, a logistic regression analysis of the dichotomous POMPP variables was done with respect to mortality. The below stated table 8 shows that Serum Albumin showed to be a significant independent factor affecting mortality $[\mathrm{p}<0.01]$.

\section{Discussion}

This study was conducted in patients admitted as a case of perforation peritonitis in the Himalayan Institute of Medical Sciences, Swami Rama Nagar and Dehradun. A total of 138 patients were recruited for the present study.

There were 8 patients aged over 65 years who had worse prognosis. [3]. In present study, $42.42+/-16.9$ years was observed as mean age of patients which was less when compared to mean ages of patients as noted in previous studies. Increased age [especially $>65$ years] has previously been shown to be associated with significantly higher mortality after perforation $[3,4,5,7$, and 8$]$.

On evaluation of the other parameters of POMPP score, $10.9 \%$ patients had albumin less than $1.5 \mathrm{gm} / \mathrm{dl}$, while $16.7 \%$ patients had BUN level more than $45 \mathrm{mg} / \mathrm{dl}$. The above findings noted in our study were similar to a previous study conducted by Kemparaj [9].

A total of $42.9 \%$ of subjects in our study suffered some form of morbidity, of which non-peptic group had $40.7 \%$ morbidity and peptic group had $45.6 \%$ morbidity. Emergency surgery for perforated ulcers was noted to be associated with a higher rate of postoperative complications [between $21 \%$ and $43 \%$ ].

In a review of literature available on the different scoring systems of GI perforations, there is around 20-50\% morbidity reported amongst cases of peptic perforations whereas nearly $30-60 \%$ morbidity has been noted amongst patients of intestinal i.e. non-peptic perforations [7, 10, 11, 12]. Complications were influenced by association with emergency surgery, inadequate post-operative care, etc. The study showed similar rates of morbidity in among total study subjects as well as in both subsections hence validating the POMPP scoring as per historic evidence.

Various complications were studied according the score allotted. Local complications that included, surgical site infection, wound dehiscence, burst abdomen were the most common comprising $27.5 \%$ which corroborates with findings from past studies by Kempraj and Bali $[9,15]$.

The number of cases suffering from systemic and respiratory complications increased with increasing score hence indicating the validity of POMPP score in predicting severity of disease. Cardiovascular and renal complications were also higher at a Score of 1 when compared to 0 thus indicating severity. However no cases were recorded to have a score of 2 or 3. There was a notably increasing trend in morbidity with increased score but there were no noted complications at score 3 , as there was a only single case with mortality. 
In our study, there was a total of $10.8 \%$ mortality noted amongst subjects which was statistically significantly associated with POMPP score. This observation was fairly comparable to past study by Shin et al had who noted $12.8 \%$ mortality in 117 patients who underwent surgery for an intestinal perforation [13]. Additionally, mortality in study by Kemparaj et al [14\%] was higher than our overall mortality whereas that noted in Bali et al was lower [7\%]. There was increased risk of mortality with increasing POMPP score like Boey \& Pulp $[16,17]$. Adequate preoperative resuscitation [with fluids, etc.], correction of electrolyte imbalances followed by an early surgical intervention, to remove the source of infection and stop further contamination, is responsible for good outcomes minimising morbidity and mortality $[15,18]$

The mean duration of hospital stay in study was 9.57 days with standard deviation of 5.83 days. Longest duration of stay was seen with POMPP score 2 group with mean of 11.67 days. Qureshi et al had similar post-operative stay of 9.6 days [19] and Chalya et al had mean stay of $8.93 \pm 6.63$ days [20]. Patients of non-peptic perforations had a longer stay of 10.51 \pm 7.05 days. Patients in the non-peptic group also showed strong positive correlation in mean stay with increasing score $[\mathrm{p}=0.019]$.

On logistic regression analysis, albumin was found to have a significant correlation with mortality with Odds ratio 0.065 and was an independent factor influencing mortality like in pervious study by Mekense et al [1] while BUN level was not significant in our study with Odds ratio 1.007 and p value 0.58 while it was affecting mortality in study by Mekense et al [1] and Moller et al [17] Age independently did not have significant effect on the prediction of mortality like in other studies [19].

POMPP scoring system involving only two investigations which is albumin and BUN level and one demographic profile that was of age, is simple tool which can satisfactorily predict mortality and morbidity in the both the group for peptic and non-peptic groups. The study was done on a small sample size which may lead to some degree of selection bias. Another possible limitation of the study may be that the sample population was taken from one part of one city, and thus it may not be representative of the population in the region or the country. Since there was one patient with POMPP score 3 which was an important statistical limitation.

Therefore, to further establish the validity of this scoring system and to make this common practice in the assessment and management of GI perforations, a large multicentre study of all geographical areas of the country is required. Another limitation is that a no standard protocol and grading followed for assessment of specific morbidity so need for further morbidity specific studies should be done.

\section{Conclusion}

Morbidity and mortality associated with gastrointestinal perforations have been shown to have a strong association with advanced age, blood urea nitrogen and serum albumin levels. Analysis of these simple clinical and biochemical parameters in the study has helped in establishment of the POMPP scoring system for risk stratification of cases of secondary peritonitis. It has been observed to be a simple, clinically applicable scoring system that may allow surgeons to rapidly predict morbidity and mortality rates in all types of gastrointestinal perforations.

Our institute along with others which are similarly placed high volume tertiary care centres, as well as smaller individual practices could benefit with risk stratification and pre-operative assessment of morbidity and mortality using a simplified scoring system like POMPP score for management of patients with secondary peritonitis.

All authors disclose no conflict of interest. The study was conducted in accordance with the ethical standards of the relevant institutional ethics committee and the Helsinki Declaration of 1975, as revised in 2000 .

\section{References}

1. Menekse E, Kocer B, Topcu R, Olmez A, Tez M, Kayaalp C. A practical scoring system to pre-dict mortality in patients with perforated peptic ulcer. World J Emerg Surg. 2015;16:1-6. https://doi.org/10.1186/s13017-015-0008-7

2. Dindo D, Demartines N, Clavien PA. Classification of surgical complications: a new proposal with evaluation in a cohort of 6336 patients and results of a survey. Ann Surg. 2004;240(2):205-213. https://doi.org/10.1097/01.sla.0000133083.54934.ae

3. Kujath P, Schwandner O, Bruch H-P. Morbidity and mortality of perforated peptic gastroduo-denal ulcer following emergency surgery. Langenbeck's Arch Surg. 2002;387(7):298-302. https://doi.org/10.1007/s00423-002-0331-9

4. Hermansson M, Von Holstein CS, Zilling T. Peptic Ulcer Perforation before and after the Intro-duction of H2-Receptor Blockers and Proton Pump Inhibitors. Scand J Gastroenterol. Taylor \& Francis; 1997 Jan 1;32(6):523-9. https://doi.org/10.3109/00365529709025093

5. Rajesh V, Chandra SS, Smile SR. Risk factors predicting operative mortality in perforated pep-tic ulcer disease. Trop Gastroenterol. 2003;24(3):148-50.

6. Sillakivi T, Lang A, Tein A, Peetsalu A. Evaluation of risk factors for mortality in surgically treated perforated peptic ulcer. Hepatogastroenterology. Greece; 2000;47(36):1765-8.

7. Kim J, Jeong S, Lee Y. Analysis of risk factors for postoperative morbidity in perforated peptic ulcer. J Gastric. 2012;12(1):26-35. https://doi.org/10.5230/jgc.2012.12.1.26 
8. Testini M, Portincasa P, Piccinni G, Lissidini G, Pellegrini F, Greco L. Significant factors asso-ciated with fatal outcome in emergency open surgery for perforated peptic ulcer. World J Gastroenterol. 2003; 9(10):2338-40. https://doi.org/10.3748/wjg.v9.i10.2338

9. Kemparaj T, Narasimhaiah NK. Our experience in gastrointestinal perforations: a retrospective study. 2017;4(2):593-7. https://doi.org/10.18203/2349-2902.isj20170198

10.Boey J, Choi SK, Poon A, Alagaratnam TT. Risk stratification in perforated duodenal ulcers. A prospective validation of predictive factors. Ann Surg. 1987; 205(1):22-6.

https://doi.org/10.1097/00000658-198701000-00005

11.Truong A, Hanna MH, Moghadamyeghaneh Z, Stamos MJ. Implications of preoperative hypo-albuminemia in colorectal surgery. World J Gastrointest Surg. 2016;8(5):353. https://doi.org/10.4240/wjgs.v8.i5.353

12. Han EC, Ryoo S-B, Park BK, Park JW, Lee SY, Oh H-K, et al. Surgical outcomes and prognos-tic factors of emergency surgery for colonic perforation: would fecal contamination increase morbidity and mortality? Int J Colorectal Dis. Germany; 2015 Nov;30(11):1495-504. https://doi.org/10.1007/s00384-015-2315-6

13.Shin R, Lee SM, Sohn B, Lee DW, Song I, Chai YJ, et al. Predictors of morbidity and mortality after surgery for intestinal perforation. Ann Coloproctol. 2016;32(6):221-7.

https://doi.org/10.3393/ac.2016.32.6.221

14.Thorsen K, Søreide JA, Søreide K. Scoring systems for outcome prediction in patients with per-forated peptic ulcer. Scand J Trauma ResuscEmerg Med 2013;21:25.

https://doi.org/10.1186/1757-7241-21-25
15.Bali RS, Verma S, Agarwal PN, Singh R, Talwar N. Perforation Peritonitis and the developing World. ISRN Surg. Hindawi Publishing Corporation; 2014;2014:1-4.

https://doi.org/10.1155/2014/105492

16.Agarwal A, Jain S, Meena LN, Jain SA, Agarwal L. Validation of Boey's score in predicting morbidity and mortality in peptic perforation peritonitis in Northwestern India. Trop Gastroenterol 2016; 36(4):256-60.

https://doi.org/10.7869/tg.300

17. Møller MH, Engebjerg MC, Adamsen S, Bendix J, Thomsen RW. The Peptic Ulcer Perforation (PULP) score: a predictor of mortality following pepticulcer perforation. A cohort study. ActaAnaesthesiol Scand. 2012;56:655-62. https://doi.org/10.1111/j.1399-6576.2011.02609.x

18.Nachiappan LM. Scoring Systems for Outcome Prediction of Patients with Perforation Peritoni-tis. J Clin Diagnostic Res. 2016;10(3):1-5. https://doi.org/10.7860/JCDR/2016/16260.7338

19.Qureshi AM, Zafar A, Saeed K, Quddus A. Predictive power of Mannheim peritonitis index. J Coll Physicians Surg Pakistan. 2005;15(11):693-6.

20.Chalya PL, Mabula JB, Koy M, McHembe MD, Jaka HM, Kabangila R, et al. Clinical profile and outcome of surgical treatment of perforated peptic ulcers in Northwestern Tanzania: A ter-tiary hospital experience. World J Emerg Surg. 2011;6:31-9. https://doi.org/10.1186/1749-7922-6-31 